\title{
Consumers' perceptions toward 3 different fermented dairy products: Insights from focus groups, word association, and projective mapping
}

\author{
Erick A. Esmerino, ${ }^{*}{ }^{1}$ Juliana P. Ferraz, ${ }^{*}$ Elson R. Tavares Filho, ${ }^{*}$ Letícia P. F. Pinto, $\dagger$ Mônica Q. Freitas, $\dagger$ \\ Adriano G. Cruz, $\ddagger$ and Helena M. A. Bolini* \\ *Food and Nutrition Department, State University of Campinas (UNICAMP), Cidade Universitária "Zeferino Vaz," s/n, Campinas, São Paulo, \\ Brazil, 13083-862 \\ †Food Technology Department, Federal Fluminense University (UFF), Rua Senador Furtado, n 121/125, Niterói, Rio de Janeiro, Brazil, \\ 20270-021 \\ łFood Department, Federal Institute of Rio de Janeiro (IFRJ), Rua Senador Furtado, n 121/125, Maracanã, Rio de Janeiro, Brazil, $20270-021$
}

\begin{abstract}
Yogurts, fermented milk beverages, and fermented milks have great similarity and are widely accepted by Brazilian population, but the factors that influence their choice and consumption are unknown. In this sense, the present study aimed to identify the main aspects involved in consumers' perception of 3 different products, comparing the findings by using the 2 fast qualitative methods, word association and projective mapping, and a standard method, focus group. The tasks were performed by different participants through graphic stimuli (word association and projective mapping) and focus interviews (focus group). Results showed that all the 3 methodologies identified numerous intrinsic and extrinsic factors that influence the consumer choices regarding fermented dairy products. Major dimensions were closely related to the sensory aspects, emotional factors, perception of benefits, and composition, among others. It is noteworthy that the stimuli related to fermented milk beverages evoked rejecting responses, possibly due to the dissociation between information and consumers' expectation. Although minor differences were observed between the number and type of dimensions that were obtained, similar conclusions can be drawn from all 3 sensory methods, which shows the relevance of qualitative and projective methods for investigation of consumers' perception. These findings can help dairy companies to provide subsidies and guidelines for the reformulation of their products, marketing strategies, and improvement in the communication between producers and consumers from different fermented dairy products.
\end{abstract}

Received December 29, 2016.

Accepted May 29, 2017.

${ }^{1}$ Corresponding author: erick.almeida@hotmail.com
Key words: consumers' perception, qualitative research, projective techniques, focus group, fermented dairy products

\section{INTRODUCTION}

The consumption of fermented dairy products in Brazil is constantly increasing, and between 2010 and 2015 the market almost doubled, reaching values close to $\mathrm{R} \$ 14.5$ billion (where $\mathrm{R} \$ 1=\mathrm{US} \$ 3.14$ ). Among fermented dairy products, yogurts and fermented milks are the most important items (CanaOnline, 2016). In addition, the production of milk beverages is one of the main options for the use of whey, especially in fermented milk beverages, which have similar sensory characteristics to yogurt and fermented milks (Siqueira et al., 2013; Farah et al., 2017).

Despite the distinct technological stages, nutritional content, and regulatory nomenclature, yogurts, fermented milk, and fermented milk beverage are found in Brazilian market with similar labels and packaging, which may influence the purchase decisions and consumption (Castro et al., 2013a; Janiaski et al., 2016). Yogurt is a popular product obtained by the protosymbiotic fermentation of milk by both Lactobacillus bulgaricus and Streptococcus thermophilus. Through the decrease of $\mathrm{pH}$ and milk coagulation by nonspecific lactic acid-fermenting bacteria, fermented milk is obtained, whereas fermented milk beverage is basically obtained from milk, whey addition, and other food ingredients (Castro et al., 2013a; Janiaski et al., 2016). Although all are well accepted, the factors that drive the choice and consumption of these products are still unknown; thus, knowledge about factors that drive choice can improve the commercialization strategies among dairy enterprises in the market.

As the selection and consumption of food is a highly complex phenomenon, influenced by sensory and non- 
sensory characteristics, understanding of consumers' perception about a product is essential and a key factor for commercial success (King and Meiselman, 2010; Santosa et al., 2013; Spinelli et al., 2015) and should be carefully investigated. In this sense, techniques based on qualitative data stand out because they focus on particular contexts and contribute to the generation of new ideas outside of the rigid context of quantitative studies. Due their open-ended structure, qualitative data allow for deeper exploration of consumers' perceptions in a natural environment requiring little or no training sessions (Jervis and Drake, 2014).

Focus groups (FG) stand out as one of the main tools in the early stages of product development and consumer research (Carey, 2015; Morgan et al., 2016), with methods based on group meetings, carefully stimulated by a moderator, in comfortable and friendly environment, to gather target audience concepts, opinions, and attitudes about certain products (Krueger and Casey, 2014; Eldesouky and Mesias, 2014). However, FG participants may not express their honest and private opinions about the topic at hand, especially when their thoughts oppose to the views of another member. In addition, FG is time-consuming and expensive, which can impair its application. In this context, the need exists for deeper access and cost-efficient methods in consumer research.

Projective techniques have been imported from other areas for application in sensory science, becoming increasingly popular among researchers (Ares and Deliza, 2010; Vidal et al., 2013; Masson et al., 2016). They consist of a set of qualitative techniques, using vague and unstructured stimuli or situations where the individual can project his or her personality, attitude, opinions, and self-concepts to give the situation some structure (Donoghue, 2000). They are considered noninvasive approaches, thus accessing private conscious and unconscious parts of the mind of the individuals, which facilitates spontaneous verbalization of the most important representations of the stimulus (Guerrero et al., 2010; Eldesouky et al., 2015).

One of the most popular projective technique in exploratory studies is the word association task (WA). It is an effective and rapid method for obtaining information on consumers' perceptions, and it consists in providing a verbal or visual stimulus, where respondents are asked to share the first thoughts and images that come to their mind when they think about the product (Piqueras-Fiszman et al., 2013; Masson et al., 2016). These associations are quite important and are supposed to be the most relevant for consumers and their decisions when related to product purchase. Positive results have been reported in the assessment of consumer perceptions of different foods (Ares et al., 2008;
Rodrigues et al., 2015; De Andrade et al., 2016) and other products, including cosmetics (Gámbaro et al., 2014).

Projective mapping (PM) is a holistic methodology based on the evaluation of global similarities and differences among products (Mielby et al., 2014). In this technique, participants receive a sheet of paper and a sample set and are instructed to evaluate the samples and place them on the sheet according to their similarities and differences, in such a way that samples that are perceived as similar should be located close to each other whereas the samples perceived to be different should be located further apart (Vidal et al., 2014). Although it has been used in sensory characterization of different categories of foods in recent years (Risvik et al., 1994; Marcano et al., 2015; Pereira et al., 2016), studies addressing the use of PM with nontaste stimuli are limited (Dehlholm et al., 2012; Mielby et al., 2014; Varela et al., 2014; Fiszman et al., 2015) or nonexistent when considering the evaluation of dairy products.

Therefore, our study aimed to assess and compare the use of different exploratory qualitative techniques to collect consumer insights of 3 different fermented dairy products [yogurt, fermented milk beverage (whey-based), and fermented milk] by using FG, WA, and PM.

\section{MATERIALS AND METHODS}

\section{Samples}

Eight cards were used as a stimulus for WA and PM (Mielby et al., 2014; Zhang et al., 2016). Whereas the sensory characteristics and product packaging were similar, each card was made with an identical image of milky-looking liquid, containing different specifications, including the technical nomenclature and requirements of Brazilian law (Ministry of Agriculture, Livestock and Food Supply, 2005, 2007). The stimuli were chosen to represent the entire segment of these fermented dairy products in the Brazilian market. The cards were printed in color images and protected by a transparent adhesive paper; the stimuli are shown in Figure 1.

Information was written in the same font and size, differentiated only by the information provided by each product, ensuring that any effect on the data would occur due to the messages given. The information was presented as follows: full fat yogurt (WYOG), low-fat yogurt (SKYOG), probiotic yogurt (definition of probiotics according to FAO/WHO, 2002), full-fat fermented milk (WFM), low-fat fermented milk (SKFM), probiotic fermented milk (PFM; definition of probiotics according to FAO/WHO, 2002), fermented milk beverage that is a milk beverage not yogurt and contains 
whey (FMB), and probiotic fermented milk beverage that is a milk beverage not yogurt and contains whey (PFMB; definition of probiotics according to FAO/ WHO, 2002). All the data were in accordance to the food labeling information and Brazilian legislation.

\section{FG}

Two focus groups lasting between 1.5 and $2 \mathrm{~h}$ each were held in a Federal Fluminense University meeting room in September 2016, with a total of 26 participants. They were recruited through email, posters, and invitations via social networks, with participants preselected by demographic information (sex and age) and consumption profile (consumption of fermented dairy products at least once a week). Each group was arranged to encourage the diversity of opinions, views, and opportunities for interaction (Carey, 2015). The profile of the focus groups participants is summarized in Table 1.
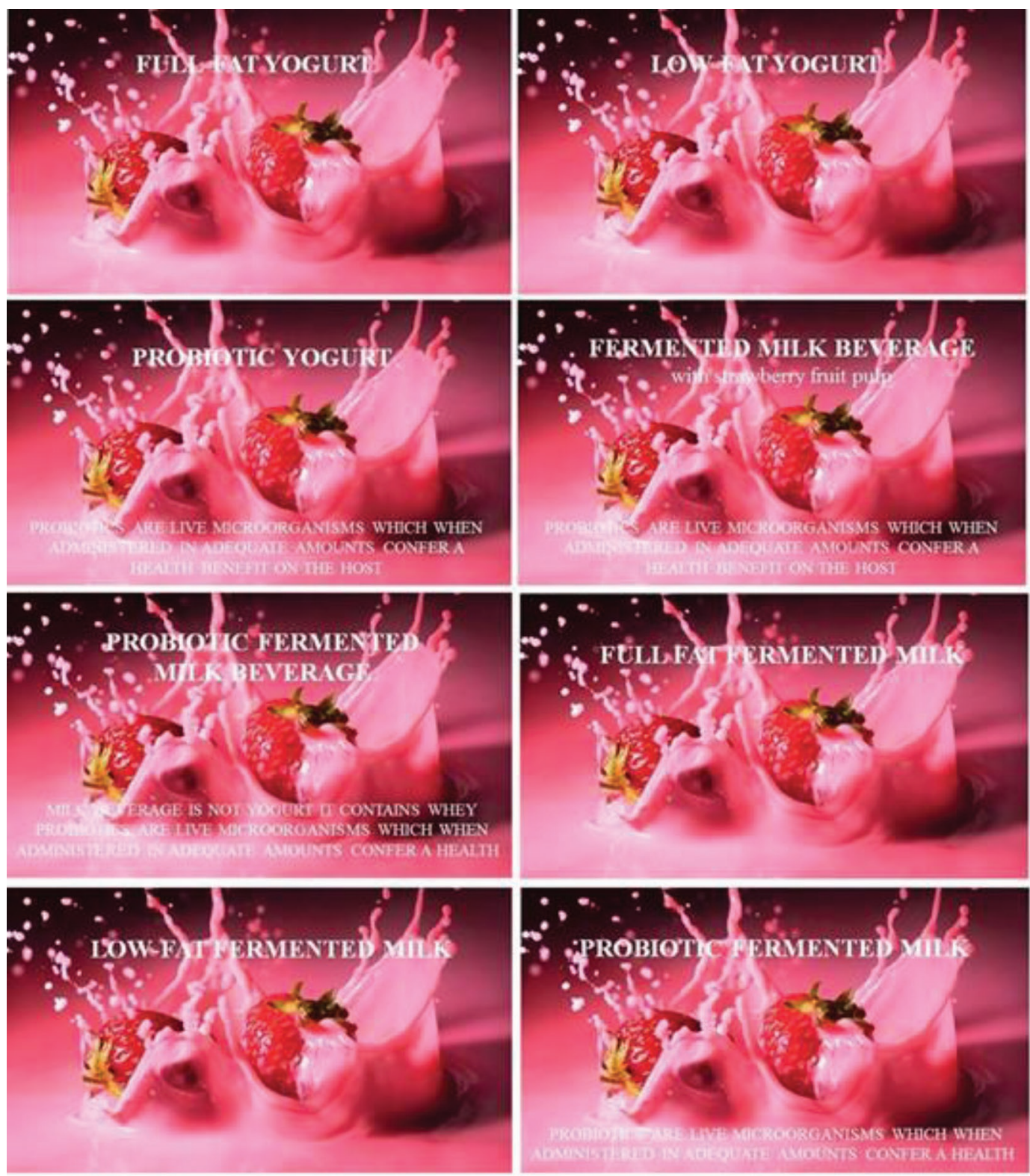

Figure 1. Representation of the 8 stimuli used in the 2 methodologies, word association task and projective mapping, for the characterization of the 3 different fermented dairy products. From left to right: WYOG (full-fat yogurt), SKYOG (low-fat yogurt), PYOG (probiotic yogurt), FMB (fermented milk beverage), PFMB (probiotic fermented milk beverage), WFM (full-fat fermented milk), SKFM (low-fat fermented milk), and PFM (probiotic fermented milk). Color version available online. 
Table 1. Sex, age, and education level of the participants of the 3 qualitative studies on different fermented dairy products

\begin{tabular}{lccc}
\hline Item & Focus group & Word association & Projective mapping \\
\hline Sex (\%) & & & \\
Male & 35.0 & 30.0 & 32.0 \\
Female & 65.0 & 70.0 & 68.0 \\
Age (yr) & 31.5 & 30.6 & 32.1 \\
Mean & 8.5 & 9.1 & 8.9 \\
SD & 35.0 & 14.0 & 10.0 \\
Education (\%) & 19.0 & 54.0 & 62.0 \\
Undergraduate & 46.0 & 32.0 & 28.0 \\
Graduate & & & \\
Postgraduate & & & \\
\hline
\end{tabular}

A moderator with extensive experience conducted the discussion and explained, in the beginning of each session, the aim of the study, characteristics of the products (liquid and ready-to-drink), voluntary participation, and audio recording for each session. In addition, terms of consent were distributed to the group, registering the confidentiality of records and informing the group the approval of the ethics committee. Although the moderator used a predefined discussion guide during the sessions, with 5 main themes (Table 2 ), the discussions were deepened when necessary. At the end of the sessions, the participants received a reward for their participation.

\section{WA Task}

The study was conducted in the city of Niterói (Brazil) in September 2016. Participants were recruited via email, posters and invitations via social network. Participants $(\mathrm{n}=50)$ were selected by consumption profile (consumption of fermented dairy products at least once a week) and asked to complete a WA task in individual cabins with adequate temperature and light. First, the participants answered a brief demographic questionnaire and then indicated the degree of familiarity with the 3 product categories (yogurts, fermented milk beverages, and fermented milk). The responses were obtained through a structured 5-point scale, where $1=$ never heard of and $5=$ extremely familiar with (Giacalone and Jaeger, 2016). The stimuli were randomly coded with 3-digit random numbers and the participants were asked to evaluate each card (stimulus) one at a time and write down spontaneously the first 4 words, terms, phrases, thoughts, feelings, images, and associations that came into their minds when they read each card with the respective information (Ares and Deliza, 2010; de Andrade et al., 2016). An open blank space was provided to fit as much information as was required.

\section{$P M$}

Similar to procedures used in the WA task, 50 different participants from WA were recruited and selected for PM. Participants completed a brief questionnaire and indicated the degree of familiarity with the products under study. They then received the cards presented in WA (encoded with 3 random digits) and were asked to place them on an A4 white sheet of paper (210 $\times 297 \mathrm{~mm}$ ) according to the perceived similarities and dissimilarities between the products and information of stimuli. Participants used their own criteria, with no

Table 2. Interview guide with themes covered by the moderator in the focus groups discussion

\begin{tabular}{ll}
\hline Section & Interview guide for focal group sessions \\
\hline Introduction & Welcome and presentations \\
& Explanation about the objectives of the study \\
& Explanation about the way the group discussion works \\
& Comments on the equipment and stages of the interview \\
& Explanation about study confidentiality \\
Themes & Contain whey? \\
& What is your opinion about these products? (information, expectation, attitude, target consumers) \\
& What is your perception about the sensory quality of these products? \\
& What kind of fermented dairy products do you consume? What makes you buy this product? \\
& What do you think about the health benefits of these products? Do you believe in the appeals contained in the product? \\
& Do you think there is enough information about the products, and about the differentiation of these products? \\
\hline
\end{tabular}


right or wrong answers. It was explained that 2 stimuli placed close together corresponded to similar perceptions, whereas different perceptions should be placed in the sheet apart from each other (Mielby et al., 2014). After positioning of the stimuli, participants were asked to write on the sheet of paper, next to the stimuli, 3 to 5 words that came into their minds and helped differentiate each product or group of products (Varela et al., 2014).

\section{Data Analysis}

$\boldsymbol{F G}$. Both FG were audio recorded and accurately transcribed, including notes and removing any identifying information. Data were analyzed by thematic analysis (Barrios et al., 2008; Santosa et al., 2013), and 2 researchers present in the session independently reviewed the transcriptions. We then compared the results, and the most relevant points of the interviews were consensually identified.

WA Task. All associations made by the participants were assessed, and the most recurring terms were selected. The results were analyzed in accordance with previous studies (Guerrero et al., 2010; de Andrade et al., 2016). After textual analysis, a categorization of the terms was carried out, and the similar terms were grouped in the same category. The categories were considered for analysis when the respective terms were mentioned by more than $5 \%$ of the participants (de Andrade et al., 2016; Masson et al., 2016). According to previous studies, this cut-off point allowed us to avoid losing a large amount of information (Guerrero et al., 2010; Vidal et al., 2013).

All results were categorized, thus obtaining 15 final categories. After that, global chi-squared was used for testing the independence between rows (categories) and columns (stimuli) of the contingency table. When the initial chi-squared was significant, it was possible to analyze within each cell to identify the source of variation of the global chi-squared (Symoneaux et al., 2012). Then, correspondence analysis (CA) was applied to the WA frequency table, which explained the clear relationship between the elicited categories and stimuli (Fonseca et al., 2016).

$\boldsymbol{P} \boldsymbol{M}$. Data were obtained from the Cartesian coordinates $\mathrm{X}$ and $\mathrm{Y}$ of each stimulus for each participant, considering the lower left corner as the origin of the coordinate system. Multiple factors analysis (MFA) was used considering the coordinate values of the samples in each individual map generated by the participants (Pagès, 2005; Valentin et al., 2012). In the next step, all words and terms elicited in the description phase were qualitatively analyzed. They were assessed independently by 2 researchers, similar to WA, who carried out the categorization of the terms. After individual evaluation of the words, a meeting between both researchers was held to determine the final categories. The mention frequency was determined by counting the number of times the term was used to describe the stimulus, and only the terms mentioned at least by $5 \%$ of the participants were used as supplementary variables in the MFA (Pereira et al., 2016).

\section{RESULTS}

\section{FG}

Table 3 presents the major findings that emerged from the focus group discussions. According to the interviews, approximately $45 \%$ of the participants were unaware of the difference between the dairy products investigated, especially in relation to the fermented milk beverage. After a brief explanation about the main technical differences between them, consumer opinion about whey-based products was assessed. For those who had prior knowledge about whey-based products, the addition of whey in the formulation exerted little influence on purchase intent, but some nutritional and sensory distinctions have been reported. On the other hand, participants who were unaware of whey-based products had neutral opinions, despite the emotional rejection and negative connotations.

Participants were also asked about the perception of product quality, based on their experience with at least 1 of the products. Most of the participants pointed out differences on the creaminess, aroma, and mild taste as main characteristics between products. The fermented milk beverage was perceived as less flavored and more watery than stirred yogurts. In contrast, the fermented milk was considered similar to milk, but with higher acidity. However, the vast majority believed that manufacturers tend to approximate the organoleptic characteristics so that consumers associate the other products with yogurt.

In another key topic, questions were raised about the consumption of the products, displaying some consumption patterns. Yogurt consumption was mainly associated with breakfast and weight loss, and considered a proper meal for some participants. It is consumed mainly by presenting health benefits, besides being a source of protein and other nutrients. For those who were unaware of the difference between the products, consumption of the other products was associated with the yogurt consumption pattern.

For participants who had prior knowledge, fermented milk beverage was perceived as a more versatile product, consumed due to high variability (various flavors and brands), as well as convenience and more affordable 
Table 3. Topics of discussion and categories that emerged from the focus group discussions

\begin{tabular}{ll}
\hline Themes of discussion & Elicited categories \\
\hline Knowledge about the products & Costs, technological process, \\
& related to dairy products, \\
& sensory attributes, sensory \\
& defects, negative feelings, \\
& neutral feelings, detriments, \\
& composition
\end{tabular}

Perception of sensory quality of the products

Consumption of fermented dairy products

Benefits and appeals of fermented dairy products
Sensory attributes, sensory defects

Consumption, composition, benefits, lifestyle, marketing
Some examples

"I did not even know there was such a difference. For me, all are yoghurt and the differences were in accordance with the marks." (woman, 46 yr old, interview 2)

"People believe milk beverage is a low-cost yoghurt, thinner." (woman, 26 yr old, interview 1)

After explanation about the main technical differences between the products

"For me, whey is just a component of the formulation. Nevertheless, I prefer yoghurt. It is thicker than fermented milk beverage." (woman, 29 yr old, interview 1)

"I have my doubts (about the quality of the product). It should not be as healthy as yoghurt; otherwise it would be better explained in the product disclosure. I never noticed, but feel cheated to buy (fermented) milk beverage instead of yoghurt. They are all very similar. This should be more explicit." (woman, 40 yr old, interview 2)

"Some are waterier (aguado), others more consistent, and I thought the differences were associated with the brand. From now on, I will pay more attention. I will give preference to yoghurt." (man, $33 \mathrm{yr}$ old, interview 2)

"The fermented milk beverages have bitter taste and are watery.

Fermented milks are generally much more acidic, while yoghurts are creamy, more flavored, and sweet." (woman, 28 yr old, interview 2)

"Today I believe that the differences (between the products) are due to the brands. The industries formulate products according to the consumer desire. The fermented milk beverage may be waterier, but it contains gum and has similar texture to yoghurt, thus consumer thinks he is consuming yoghurt." (woman, 29 yr old, interview 1)

"I consider them healthy and suitable products for breakfast. It's better than eating bread, cake...they are less caloric." (woman, 58 yr old, interview 2)

"I always eat my yoghurt in the morning, pure or together with some fruit. Sometimes I replace dinner by yoghurt. It helps dieting." (woman, 29 yr old, interview 1)

"I consume yoghurt because it is a healthy product, source of calcium, protein and it is easy to digest. I do not know if other products have similar benefits." (woman, 58 yr old, interview 2)

"I consume fermented milk beverage due to its various flavors. As they are waterier, are more practical to consume." (man, 27 yr old, interview 1)

"Fermented milk is popular with children, and industry is trying to reach the adult public. Some time ago, Yakult $40^{1}$ emerged on the market." (woman, 58 years old, interview 2 .

Marketing, sensory attributes, "Look at the example of Activia ${ }^{2}$ (probiotic fermented milk); advertising lifestyle is directed to women seeking to reduce bloating and to regulate intestinal transit. It seems that is a product aimed only at women." (man, $27 \mathrm{yr}$ old, interview 1)

"Most of the fermented milk is directed to children. The slogan of living lactobacilli helps the body is anchored in people's minds even after they grow up." (woman, 26 yr old, interview 1)

"I prefer the full-fat product, it is tastier, but I can change it for a similar light product with less calories if I'm in weight loss process." (woman, 46 yr old, interview 2)

"It may be written on the package which is what, but as packages are similar, confusion can happen, thus consumer can buy a product thinking it was the other." (man, 26 yr old, interview 1)

"You arrive at the market and the products are all mixed on the shelves. The products are separated by brands rather than types, which confuses consumers even more." (woman, 29 yr old, interview 1)

"Consumers pay more attention to the expiration date and caloric values than to other information." (man, 28 yr old, interview 2).

\footnotetext{
${ }^{1}$ Yakult 40, Yaklult S/A Industrai e Comercio, Sao Bernardo, SP, Brazil.
}

${ }^{2}$ Activia, Danone Brasil, Pocos de Caldas, MG, Brazil.

prices when compared with other products. However, most participants believe that the sales of fermented milk beverages are driven by consumer misinformation.
In contrast, fermented milk was a familiar product to most participants, although for the clear majority it was associated with specific brands, with well-defined 
Table 4. Contingency table with the main categories and example of associations elicited by consumers to each of the fermented dairy products; the number of citations per stimuli and results of the chi-squared per cell test are presented ${ }^{1,2}$

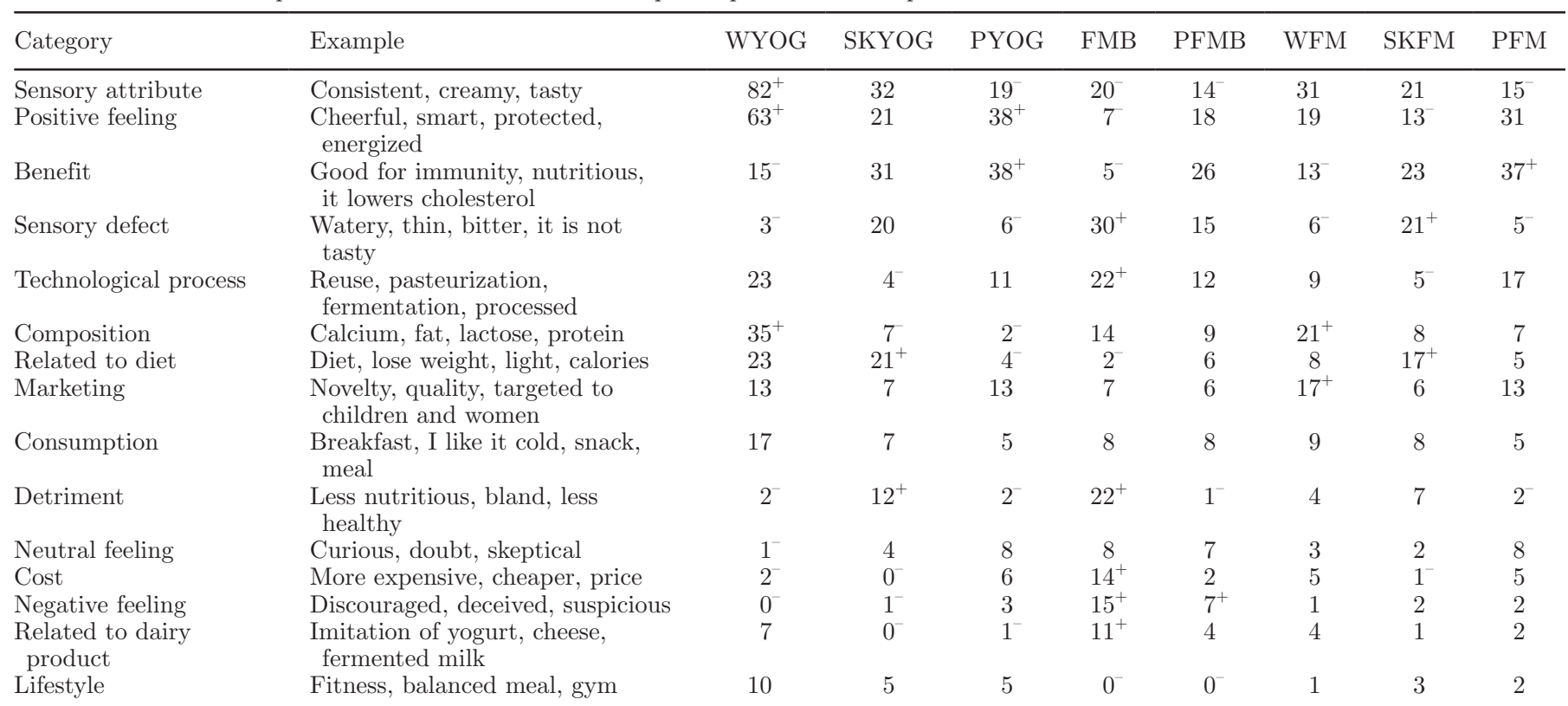

${ }^{1}$ Plus $(+)$ or minus $(-)$ following values represents the observed value higher or lower than the expected theoretical value $(P<0.05)$.

${ }^{2} \mathrm{WYOG}=$ full-fat yogurt; SKYOG = low-fat yogurt; PYOG = probiotic yogurt; FMB = fermented milk beverage; PFMB = probiotic fermented milk beverage; WFM = full-fat fermented milk; SKFM = low-fat fermented milk; PFM = probiotic fermented milk.

flavor, aimed at children. Emotional connotations, such as nostalgia and concern, were observed. As for the benefits, respondents believed in the health claims and appeals assigned to the products, especially the light, zero fat, and probiotic products. Nevertheless, they believed that the products have specific target groups, and the marketing does not encourage consumption in another niche market.

Regarding the differences between the products, about $85 \%$ of the participants believed that the information on the labels was not clear and visible to allow differentiation between products. Additionally, consumers did not usually read the entire label, and several brands are placed together on the shelves, which causes further confusion.

\section{WA Task}

The level of familiarity of the participants with the different types of fermented dairy products was assessed before the WA performance. According to the findings, yogurt showed the highest average (4.00, know a fair amount) among the products with significant differences $(P \leq 0.05)$, demonstrating the high degree of familiarity of the participants with this product. In contrast, the fermented milk and fermented milk beverage presented lower mean values (3.33 and 2.88, corresponding to heard of it and know a little, respectively), with no significant differences $(P \leq 0.05)$ between them, demonstrating the most superficial relationship between these products and participants.

In the WA findings, 1,394 terms were generated and used for developing the methodology. Fifteen categories were identified using the associations obtained for all stimuli investigated, and all terms were ranked within these categories. The associations were highly significant to the stimuli, suggesting that the information significantly affected consumers' perception of the different fermented dairy products $\left(\chi^{2}=483.76, P<\right.$ 0.001). Moreover, the application of the chi-squared per cell test in the contingency table also made it possible to identify which categories were more used or less used for each type of stimulus. Table 4 shows the 15 categories, examples of terms, and their respective frequencies.

To assess the profile and identify the correlations between stimuli and categories based on the frequency of mentions by consumers, CA was applied and the results are shown in Figure 2. This is a descriptive or exploratory technique designed to examine contingency tables, with 2 entries containing correspondence measures between rows and columns. The variables are projected in the factor-plane, providing a visual and simultaneous representation of all data (Pontual et al., 2017). The first 2 dimensions of CA accounted for approximately $72 \%$ of the total experimental variance. 
According to WA, the sample FMB was characterized mainly by the categories negative feelings, detriments, and related to dairy products. The stimuli related to probiotic samples (PYOG and PFM) were perceived similarly to each other, characterized by the categories benefits and neutral feelings. The stimulus PFMB, characterized by the categories marketing, sensory defects, and neutral feelings, was classified between the conventional product (FMB) and the low-fat samples (SKYOG and SKFM). The low-fat samples, on the other hand, were characterized by the categories marketing, positive feelings, technological process, related to diet, and consumption. The stimulus WYOG, containing the information full-fat yoghurt, was characterized by presenting relevant terms by the categories sensory attributes and composition, whereas WFM was highly correlated with the attributes consumption, sensory attributes, and related to diet.

\section{PM}

Similar to WA, the level of familiarity of the participants was evaluated before PM performance, and the results showed similar trend. Yogurt was the most familiar dairy product, with the highest average (3.86, from very close to know a fair amount), and it was statistically different from the other products $(P \leq$
0.05). No significant differences were observed between fermented milk beverage (2.81) and fermented milk (2.86).

According to PM, it was possible to determine 10 different main categories related to fermented dairy products. The most cited categories were sensory attributes, positive feelings, sensory defects, and related to diet, which is very similar to the results of WA, although PM cited fewer categories. The first 2 dimensions of the MFA accounted for approximately $78 \%$ of the differences between the stimuli, as shown in Figure 3.

The results show that consumers have grouped stimuli according to the category and added appeal. The full-fat samples, WYOG and WFM, were characterized similarly by the categories composition, consumption, sensory attributes, and positive feelings. The probiotic samples, PYOG and PFM, were characterized by marketing and benefits. The low-fat samples SKYOG and SKFM were similarly grouped and characterized by the categories related to diet and sensory defects. Regarding the fermented dairy beverage, the most frequently related categories were negative feelings and detriments.

\section{DISCUSSION}

To the best of our knowledge, this is the first study to investigate consumer perception of different categories

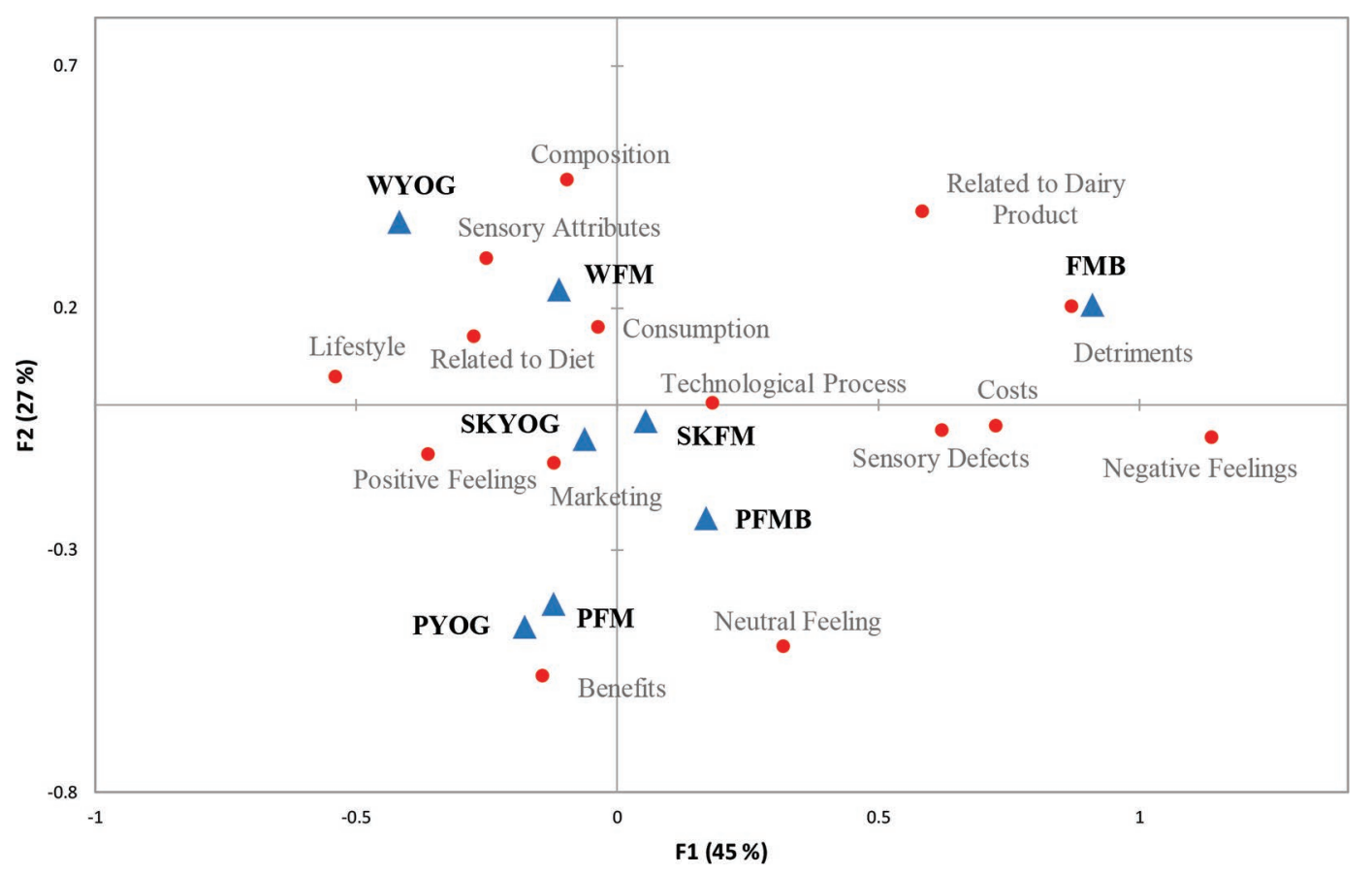

Figure 2. Correspondence analysis of contingency table, crossing 8 different stimuli of fermented dairy products and main categories cited by consumers. Triangles represent the different samples (stimuli) and circles represent the projection of the categories used. WYOG $=$ full-fat yogurt; SKYOG = low-fat yogurt; PYOG = probiotic yogurt; FMB = fermented milk beverage; PFMB = probiotic fermented milk beverage; $\mathrm{WFM}=$ full-fat fermented milk; SKFM = low-fat fermented milk; and PFM = probiotic fermented milk. Color version available online. 
of fermented dairy products through distinct qualitative techniques, such as WA, FG, and PM.

As we observed, the intrinsic characteristics expected for the different products were responsible for many of the indications brought up by participants in all tests. The category sensory attributes, correlated with terms such as strawberry, sour, fermented flavor, creamy, and consistent, was the most frequently mentioned category in both WA and PM, demonstrating the importance of this dimension for differentiation and choice of products. The category sensory defects was the fourth most cited in the WA, and the second most cited in the PM, associated with the attributes watery, tasteless, and bitter. Endorsed by the responses from FG, it is noted that some of the main expected differences between products referred to their quality and sensory characteristics. In this regard, our results aligned with previous studies.

According to Janiaski et al. (2016), the sensory properties play a key role in the marketing of yogurt and whey beverages among consumers. Flavor attributes influenced by organic acids and peptides derived from fermentation and other flavor compounds are also relevant for the choice of these products (Hekmat and
Reid 2006; Soukoulis et al., 2007). However, texture attributes play an important and decisive role in the final quality of dairy products (Ares et al., 2008; Castro et al., 2013a; Morell et al., 2015). In addition, attributes such as creaminess, body, and viscosity have great importance for the acceptability of semisolid dairy products (Soukoulis et al., 2010). Thus, an imminent need exists for optimization of the formulation, especially concerning the texture attributes for improving acceptance of these products, as the main difference between the products is related to the addition of whey and the use of different lactic acid cultures, which have a direct influence on viscosity and texture of the products (Castro et al., 2013b; Mani-López et al., 2014).

Equally important, emotions and feelings evoked by stimuli had a great effect on product differentiation. The category positive feelings, second and third most cited category in WA and PM, respectively, and mentioned by some participants in FG though with no direct approach, was associated with the terms smart, cheerful, healthy, protected, and energized. It is also suggested that it is correlated with the category benefits, mainly characterizing the probiotic samples in both individual tests.

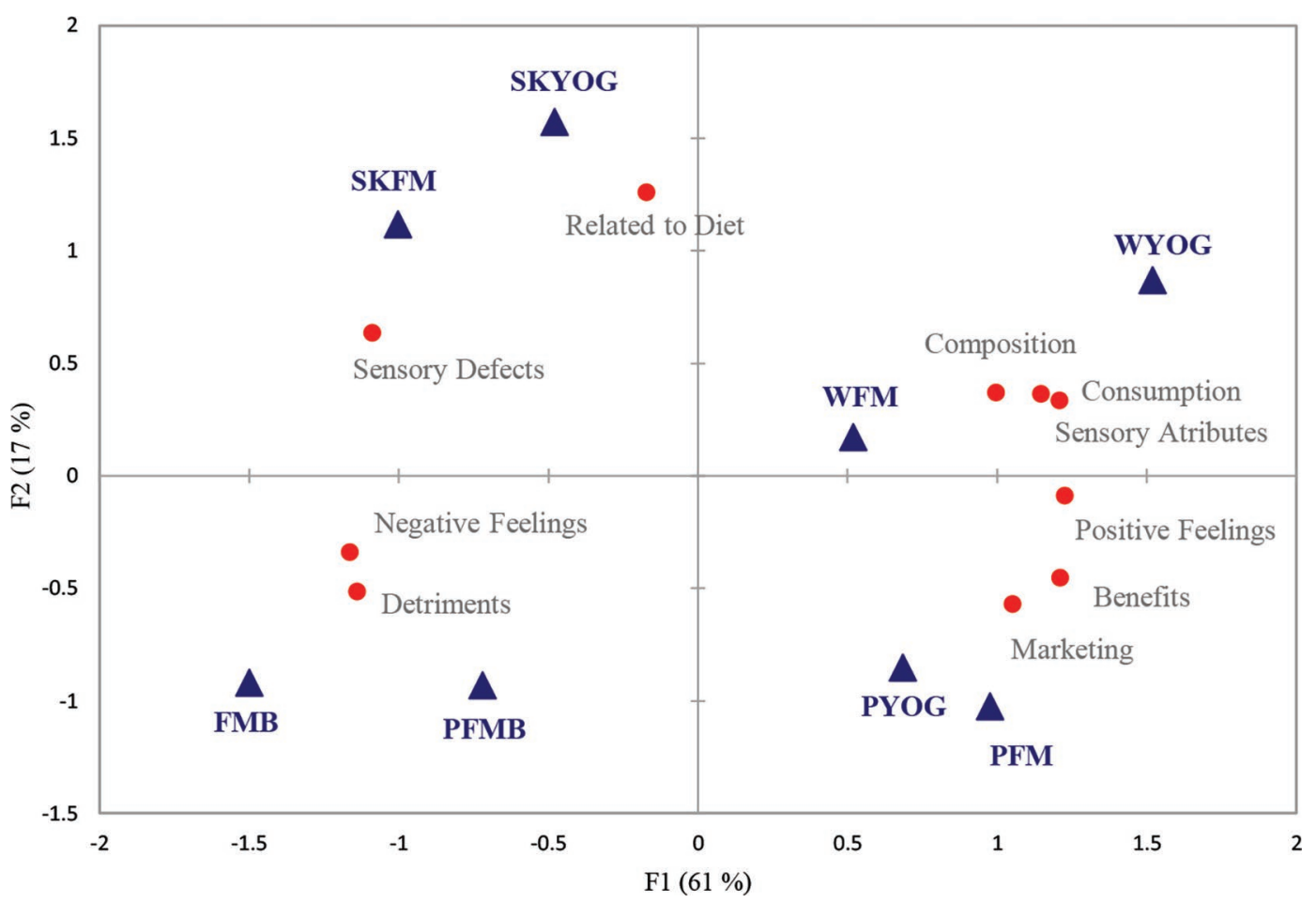

Figure 3. Results of the projective mapping task in the first and second dimensions of the multiple factor analysis for 8 different stimuli of fermented dairy products: triangles represent the different samples (stimuli) and circles represent the projection of the categories used in the description phase. WYOG = full-fat yogurt; SKYOG = low-fat yogurt; PYOG = probiotic yogurt; FMB = fermented milk beverage; PFMB $=$ probiotic fermented milk beverage; WFM = full-fat fermented milk; SKFM = low-fat fermented milk; and PFM = probiotic fermented milk. Color version available online. 
In contrast, negative feelings, another important category, was also pointed out through both projective techniques and cited indirectly by participants in FG. It was related to the terms cheated, sad, suspicious, discouraged, deceived, and worried, mainly associated with the stimulus FMB in the WA test, and the stimuli FMB and PFMB in the PM test. These results may be due to the dissociation between yogurt images and information in the given stimuli of fermented milk beverages.

Consumers consider yogurt a food with a positive and healthy image (Perina et al., 2015; Caleja et al., 2016), presenting similar characteristics to fermented milk beverages and fermented milks (Wang et al., 2012; Castro et al., 2013a), with potential benefits reported in clinical studies (Lollo et al., 2013). However, in cases of disconfirming information, which may have occurred after assessing information required by Brazilian legislation, consumers may have changed their perception of fermented milk beverages, adopting a more negative perception (Cardello and Sawyer 1992). The assimilation-contrast effect is one of the most studied disconfirmation effects in sensory analysis (Piqueras-Fiszman and Spence, 2015; Schouteten et al., 2016). When little discrepancies occur between a product under evaluation and a standard product for the consumer, the assimilation effect may occur and no effect on the hedonic evaluation will be noted; however, the contrast effect happens in high-discrepancy situations, generating surprise and discomfort (Davidenko et al., 2015).

Additionally, the 3 exploratory methods linked to categories such as composition, with references to calcium content, sugar, fat, and protein; related to diet, with citations for use in diets and weight loss; consumption, associated with the habits and periods of consumption; and marketing, related to brands and target groups.

The consumption of fermented dairy products has grown worldwide. Brazilian people consume it as a snack, mostly for breakfast (Thompson et al., 2007; Janiaski et al., 2016). The nutritional content, including protein, calcium, and fat, is associated with potential healthful effects; it is a source of potassium and vitamins, particularly thiamine and riboflavin (Morell et al., 2015; Lopez-Garcia et al., 2015). Moreover, it is believed that consumption of functional varieties, such as probiotics, has practical effects, even if they are used as marketing strategies with a different price and target specific groups (Barrios et al., 2008).

It is important to emphasize that the interviews in FG raised an important discussion on the communication between dairy industries and consumers. As elicited by the participants, although information was arranged according to the requirements established by law, it is believed that the majority of consumers do not understand information provided by suppliers in the same way. Barrios et al. (2008) also pointed out that more information should be present on the product's label.

Studies on yogurt have suggested the existence of different types of consumers with different forms of processing information on the label (Ares et al., 2014). Some consumers tend to perform simple choices based on superficial investigations, founded on intuitive thinking style, whereas other consumers conduct more rational and deep searches, making comparisons between products before making their choices (Fonseca et al., 2016). Thus, to develop persuasive communication strategies, the way in which consumers interpret the information should be carefully investigated (Ares et al., 2014; Mawad et al., 2015).

Overall, our findings suggest that all methodologies were valid and able to express clearly the major categories responsible for the characterization of different fermented dairy products according to consumer perception. These results match recent studies such as Masson et al. (2016), who observed that individual investigations generally have similar exploratory capacity of collective conveyances as the focal interviews; however, it is worth mentioning some peculiarities inherent to the present study.

Some dimensions, such as technological process, costs, related to dairy, and lifestyle, were mentioned only by participants in WA and FG, which covered all categories addressed in PM. Projective mapping took a less comprehensive approach, covering the smallest number of dimensions, possibly because of it its experimental design and holistic basis, as participants tend to look for the most prominent stimuli aspects. However, it is important to emphasize that PM presents high-quality results because it exposes the most objective dimensions, considered relevant for the characterization and product differentiation, especially when the product is not subjected to sensory evaluation (Varela et al., 2014; Fiszman et al., 2015).

\section{CONCLUSIONS}

Although minor differences have occurred in some of the categories elicited by consumers, an agreement between the methodologies was observed regarding the most relevant items. Our findings indicated that the circumstances that influence product choice and consumption are multidimensional; they are mainly related to intrinsic characteristics (sensory attributes) and extrinsic characteristics, including psychological aspects (emotions and feelings), perception of benefits, health claims, and marketing appeals. Using interviews in focus groups made it possible to obtain robust and in-depth 
results; however, projective techniques provided the key dimensions involved in product differentiation with less experimental and time-consuming efforts than FG, thus proving to be a rapid and low-cost alternative to assess consumer perception about fermented dairy products. Finally, we suggest that WA and PM can be effective tools for dairy companies with limited financial and human resources, focused on new consumer markets. They may provide a preliminary insight to define the most effective and economic strategy to introduce their products with a minimal risk of failure in the consumer market.

\section{ACKNOWLEDGMENTS}

We thank $\mathrm{CNPq}$ for the financial support granted to the project.

\section{REFERENCES}

Ares, G., and R. Deliza. 2010. Studying the influence of package shape and colour on consumer expectations of milk desserts using word association and conjoint analysis. Food Qual. Prefer. 21:930-937.

Ares, G., A. Giménez, and A. Gámbaro. 2008. Understanding consumers' perception of conventional and functional yogurts using word association and hard laddering. Food Qual. Prefer. 19:636-643.

Ares, G., F. Mawad, A. Giménez, and A. Maiche. 2014. Influence of rational and intuitive thinking styles on food choice: Preliminary evidence from an eye-tracking study with yogurt labels. Food Qual. Prefer. 31:28-37.

Barrios, E. X., S. Bayarri, I. Carbonell, L. Izquierdo, and E. Costell. 2008. Consumer attitudes and opinions toward functional foods: A focus group study. J. Sens. Stud. 23:514-525.

Caleja, C., L. Barros, A. L. Antonio, M. Carocho, M. B. P. P. Oliveira, and I. C. F. R. Ferreira. 2016. Fortification of yogurts with different antioxidant preservatives: A comparative study between natural and synthetic additives. Food Chem. 210:262-268.

CanaOnline. 2016. O mercado de iogurtes no Brasil: crescendo além da crise. Accessed Feb. 3, 2017. http://www.canaonline.com.br/ conteudo/o-mercado-de-iogurtes-no-brasil-crescendo-alem-da-crise .html\#.WRYyPOvyv4Y.

Cardello, A. V., and F. M. Sawyer. 1992. Effects of disconfirmed consumer expectations on food acceptability. J. Sens. Stud. 7:253-277.

Carey, M. A. 2015. Focus groups. Pages 274-279 in International Encyclopedia of the Social \& Behavioral Sciences. 2nd ed. Elsevier, Oxford, UK.

Castro, W. F., A. G. Cruz, M. S. Bisinotto, L. M. R. Guerreiro, J. A. F. Faria, H. M. A. Bolini, R. L. Cunha, and R. Deliza. 2013a. Development of probiotic dairy beverages: Rheological properties and application of mathematical models in sensory evaluation. J. Dairy Sci. 96:16-25.

Castro, W. F., A. G. Cruz, D. Rodrigues, G. Ghiselli, C. A. Oliveira, J. A. Faria, and H. T. Godoy. 2013b. Short communication: Effects of different whey concentrations on physicochemical characteristics and viable counts of starter bacteria in dairy beverage supplemented with probiotics. J. Dairy Sci. 96:96-100.

Davidenko, O., J. Delarue, A. Marsset-Baglieri, G. Fromentin, D. Tome, N. Nadkarni, and N. Darcel. 2015. Assimilation and contrast are on the same scale of food anticipated-experienced pleasure divergence. Appetite 90:160-167.

de Andrade, J. C., L. De Aguiar Sobral, G. Ares, and R. Deliza. 2016. Understanding consumers' perception of lamb meat using free word association. Meat Sci. 117:68-74.

Dehlholm, C., P. B. Brockhoff, L. Meinert, M. D. Aaslyng, and W. L. P. Bredie. 2012. Rapid descriptive sensory methods - Comparison of free multiple sorting, partial napping, napping, flash profiling and conventional profiling. Food Qual. Prefer. 26:267-277.

Donoghue, S. 2000. Projective techniques in consumer research. J. Fam. Ecol. Consum. Sci. 28:47-53.

Eldesouky, A., and F. Mesias. 2014. An insight into the influence of packaging and presentation format on consumer purchasing attitudes towards cheese: a qualitative study. Span. J. Agric. Res. $12: 305-312$.

Eldesouky, A., A. Pulido, and F. Mesias. 2015. The Role of packaging and presentation format in consumers' preferences for food: An application of projective techniques. J. Sens. Stud. 30:360-369.

FAO/WHO. 2002. Joint FAO/WHO working group report on drafting guidelines for the evaluations of probiotics in food. Food and Agricultural Organization of the United Nations and World Health Organization, Rome, Italy.

Farah, J. S., C. B. Araujo, and L. Melo. 2017. Analysis of yoghurts', whey-based beverages' and fermented milks' labels and differences on their sensory profiles and acceptance. Int. Dairy J. 68:17-22.

Fiszman, S., E. Carrillo, and P. Varela. 2015. Consumer perception of carriers of a satiating compound. Influence of front-of-package images and weight loss-related information. Food Res. Int. 78:88-95.

Fonseca, F. G., E. A. Esmerino, E. R. Filho, J. P. Ferraz, A. G. Da Cruz, and H. M. Bolini. 2016. Novel and successful free comments method for sensory characterization of chocolate ice cream: A comparative study between pivot profile and comment analysis. J. Dairy Sci. 99:3408-3420.

Gámbaro, A., E. Parente, A. Roascio, and L. Boinbaser. 2014. Word association technique applied to cosmetic products - A case study. J. Sens. Stud. 29:103-109.

Giacalone, D., and S. R. Jaeger. 2016. Better the devil you know? How product familiarity affects usage versatility of foods and beverages. J. Econ. Psychol. 55:120-138.

Guerrero, L., A. Claret, W. Verbeke, G. Enderli, S. Zakowska-Biemans, F. Vanhonacker, S. Issanchou, M. Sajdakowska, B. S. Granli, L. Scalvedi, M. Contel, and M. Hersleth. 2010. Perception of traditional food products in six European regions using free word association. Food Qual. Prefer. 21:225-233.

Hekmat, S., and G. Reid. 2006. Sensory properties of probiotic yogurt is comparable to standard yogurt. Nutr. Res. 26:163-166.

Janiaski, D. R., T. C. Pimentel, A. G. Cruz, and S. H. Prudencio. 2016. Strawberry-flavored yogurts and whey beverages: What is the sensory profile of the ideal product? J. Dairy Sci. 99:5273-5283.

Jervis, M. G., and M. A. Drake. 2014. The use of qualitative research methods in quantitative science: A review. J. Sens. Stud. 29:234247

King, S. C., and H. L. Meiselman. 2010. Development of a method to measure consumer emotions associated with foods. Food Qual. Prefer. 21:168-177.

Krueger, R. A., and M. A. Casey. 2014. Focus Groups: A Practical Guide for Applied Research. Sage Publications, Thousand Oaks, CA.

Lollo, P. C. B., C. S. de Moura, P. N. Morato, A. G. Cruz, W. D. F. Castro, C. B. Betim, L. Nisishima, J. D. A. F. Faria, M. Maróstica Junior., C. O. Fernandes, and J. Amaya-Farfan. 2013. Probiotic yogurt offers higher immune-protection than probiotic whey beverage. Food Res. Int. 54:118-124.

Lopez-Garcia, E., L. Leon-Munoz, P. Guallar-Castillon, and F. Rodriguez-Artalejo. 2015. Habitual yogurt consumption and healthrelated quality of life: A prospective cohort study. J. Acad. Nutr. Diet. 115:31-39.

Mani-López, E., E. Palou, and A. López-Malo. 2014. Probiotic viability and storage stability of yogurts and fermented milks prepared with several mixtures of lactic acid bacteria. J. Dairy Sci. 97:2578-2590.

Marcano, J., G. Ares, and S. Fiszman. 2015. Comparison of partial and global projective mapping with consumers: A case study with satiating cheese pies. Food Res. Int. 67:323-330.

Masson, M., J. Delarue, S. Bouillot, J.-M. Sieffermann, and D. Blumenthal. 2016. Beyond sensory characteristics, how can we identify subjective dimensions? A comparison of six qualitative meth- 
ods relative to a case study on coffee cups. Food Qual. Prefer. 47:156-165.

Mawad, F., M. Trías, A. Giménez, A. Maiche, and G. Ares. 2015. Influence of cognitive style on information processing and selection of yogurt labels: Insights from an eye-tracking study. Food Res. Int. 74:1-9.

Mielby, L. H., H. Hopfer, S. Jensen, A. K. Thybo, and H. Heymann. 2014. Comparison of descriptive analysis, projective mapping and sorting performed on pictures of fruit and vegetable mixes. Food Qual. Prefer. 35:86-94.

Ministry of Agriculture, Livestock and Food Supply. 2005. Brazilian Normative Instruction 16/2005: Technical Regulation on Identity and Quality of Whey-based Drinks. D.O.U. Official Diary of the Union, Brasília, Brazil.

Ministry of Agriculture, Livestock and Food Supply. 2007. Brazilian Normative Instruction 46/2007: Technical Regulation of Identity and Quality of Fermented Milks. D.O.U. Official Diary of the Union. Brasília, Brazil.

Morell, P., B. Piqueras-Fiszman, I. Hernando, and S. Fiszman. 2015. How is an ideal satiating yogurt described? A case study with added-protein yogurts. Food Res. Int. 78:141-147.

Morgan, E. H., P. Vatucawaqa, W. Snowdon, A. Worsley, A. D Dangour, and K. Lock. 2016. Factors influencing fruit and vegetable intake among urban Fijians: A qualitative study. Appetite 101:114-118.

Pagès, J. 2005. Collection and analysis of perceived product interdistances using multiple factor analysis: Application to the study of 10 white wines from the Loire valley. Food Qual. Prefer. 16:642649

Pereira, E. P. R., R. N. Cavalcanti, E. A. Esmerino, R. Silva, L. R. M. Guerreiro, R. L. Cunha, H. M. A. Bolini, M. A. Meireles, J. A. F. Faria, and A. G. Cruz. 2016. Effect of incorporation of antioxidants on the chemical, rheological, and sensory properties of probiotic petit suisse cheese. J. Dairy Sci. 99:1762-1772.

Perina, N. P., D. Granato, C. Hirota, A. G. Cruz, C. S. B. Bogsan, and M. N. Oliveira. 2015. Effect of vegetal-oil emulsion and passion fruit peel-powder on sensory acceptance of functional yogurt. Food Res. Int. 70:134-141.

Piqueras-Fiszman, B., and C. Spence. 2015. Sensory expectations based on product-extrinsic food cues: An interdisciplinary review of the empirical evidence and theoretical accounts. Food Qual. Prefer. 40:165-179.

Piqueras-Fiszman, B., C. Velasco, A. Salgado-Montejo, and C. Spence, 2013. Using combined eye tracking and word association in order to assess novel packaging solutions: A case study involving jam jars. Food Qual. Prefer. 28:328-338.

Pontual, I., G. V. Amaral, E. A. Esmerino, T. C. Pimentel, M. Q. Freitas, R. K. Fukuda, I. L. Sant'ana, L. G. Silva, and A. G. Cruz. 2017. Assessing consumer expectations about pizza: A study on celiac and non-celiac individuals using the word association technique. Food Res. Int. 94:1-5.

Risvik, E., J. A. Mcewan, J. S. Colwill, R. Rogers, and D. H. Lyon 1994. Projective mapping: A tool for sensory analysis and consumer research. Food Qual. Prefer. 5:263-269.

Rodrigues, H., J. Ballester, M. P. Saenz-Navajas, and D. Valentin. 2015. Structural approach of social representation: Application to the concept of wine minerality in experts and consumers. Food Qual. Prefer. 46:166-172.

Santosa, A. M., E. J. Clow, N. D. Sturzenberger, and J.-X. Guinard. 2013. Knowledge, beliefs, habits and attitudes of California consumers regarding extra virgin olive oil. Food Res. Int. 54:21042111.

Schouteten, J. J., H. De Steur, S. De Pelsmaeker, S. Lagast, J. G. Juvinal, I. De Bourdeaudhuij, W. Verbeke, and X. Gellynck. 2016. Emotional and sensory profiling of insect-, plant- and meat-based burgers under blind, expected and informed conditions. Food Qual. Prefer. 52:27-31.

Siqueira, A. M. O., E. C. L. Machado, and T. L. M. Stamford. 2013 Dairy beverage containing cheese whey and fruit. Cienc. Rural 43:1693-1700.

Soukoulis, C., E. Lyroni, and C. Tzia. 2010. Sensory profiling and hedonic judgment of probiotic ice cream as a function of hydrocolloids, yogurt and milk fat content. LWT Food Sci. Technol. (Campinas) 43:1351-1358.

Soukoulis, C., P. Panagiotidis, R. Koureli, and C. Tzia. 2007. Industrial yogurt manufacture: Monitoring of fermentation process and improvement of final product quality. J. Dairy Sci. 90:2641-2654.

Spinelli, S., C. Masi, G. P. Zoboli, J. Prescott, and E. Monteleone. 2015. Emotional responses to branded and unbranded foods. Food Qual. Prefer. 42:1-11.

Symoneaux, R., M. V. Galmarini, and E. Mehinagic. 2012. Comment analysis of consumer's likes and dislikes as an alternative tool to preference mapping. A case study on apples. Food Qual. Prefer. 24:59-66.

Thompson, J. L., K. Lopetcharat, and M. A. Drake. 2007. Preferences for commercial strawberry drinkable yogurts among African American, Caucasian, and Hispanic consumers in the United States. J. Dairy Sci. 90:4974-4987.

Valentin, D., S. Chollet, M. Lelièvre, and H. Abdi. 2012. Quick and dirty but still pretty good: A review of new descriptive methods in food science. Int. J. Food Sci. Technol. 47:1563-1578.

Varela, P., L. Antúnez, R. S. Cadena, A. Giménez, and G. Ares. 2014. Attentional capture and importance of package attributes for consumers' perceived similarities and differences among products: A case study with breakfast cereal packages. Food Res. Int. 64:701710 .

Vidal, L., G. Ares, and A. Giménez. 2013. Projective techniques to uncover consumer perception: Application of three methodologies to ready-to-eat salads. Food Qual. Prefer. 28:1-7.

Vidal, L., R. S. Cadena, L. Antúnez, A. Giménez, P. Varela, and G. Ares. 2014. Stability of sample configurations from projective mapping: How many consumers are necessary? Food Qual. Prefer. 34:79-87.

Wang, S., H. Zhu, C. Lu, Z. Kang, Y. Luo, L. Feng, and X. Lu. 2012. Fermented milk supplemented with probiotics and prebiotics can effectively alter the intestinal microbiota and immunity of host animals. J. Dairy Sci. 95:4813-4822.

Zhang, T., K. Lusk, M. Mirosa, and I. Oey. 2016. Understanding young immigrant Chinese consumers' freshness perceptions of orange juices: A study based on concept evaluation. Food Qual. Prefer. 48:156-165. 